\title{
De vuelta
}

\section{John Crowley, Brian Durán-Fuentes}

Taylor salió a fumar un cigarrillo. A pesar de que las desconsideradas extremidades de los borrachos estaban destrozando la casa, sin percatarse de que habían pateado un librero con tanta fuerza al bailar como para romper madera, o que se sentaban de golpe en los ya desgastados sillones y sillas desplegables, o que arrancaban el papel tapiz con la minuciosa y malvada insensatez de la que sólo los borrachos son capaces, y aunque a nadie le hubiera importado un carajo que fumara adentro, Taylor necesitaba una poca de calma en el patio.

Había un columpio con un par de cojines manchados a la izquierda de la puerta y una silla de mimbre con el respaldo roto a la derecha. Taylor eligió la silla y al sentarse sacó de su bolso un encendedor de fantasía. El encendedor tenía forma de lámpara para soldar y emitía una pequeña flama azul más efectiva que la de los encendedores tradicionales frente a vientos fuertes, pero también consumía más gas butano, por lo que por lo general prefería gorrearle el fuego a alguien más cuando podía.

Una vez que encendió el cigarrillo, tomó la oportunidad de observar el vecindario en donde transcurría la fiesta. La casa estaba ubicada en una calle bien iluminada y tenía un patio de enfrente lindo y grande, con una distancia decente entre ambas casas a los lados. Una de estas casas estaba en venta, la otra ya estaba vendida. Este vecindario sufría de un proceso de desvalorización a medida que todos los habitantes suburbanos que habían huído de la gran ciudad, ahora huían hacia complejos habitacionales mucho mejores y más nuevos en otras localidades de Dallas-Forth Worth.

La noche era fresca y amenazaba con llover. Taylor cargaba consigo una sombrilla por si acaso, pero ésta yacía inerte en su coche. Mientras que su humo se desvanecía lateralmente ante el ventilador, el cual parecía odiar sus cuantos intentos de materializar aros de humo, Taylor miraba esto como una metáfora de su vida, como tormentas o castillos de arena o mamadas así. La puerta se abrió de par en par e interrumpió sus pensamientos.

“¡Holaaaaaa!” dijo Bradly. "¡Pensé que te encontraría aquí!” Caminó hacia donde ella estaba pero como no habían más sillas, sólo se quedó parado junto al barandal, de vez en vez apoyándose en un poste y moviendo los pies. Bradley había estado bebiendo consistentemente las últimas tres horas. "Como le dijo la marrana a la larga, ¿Por qué la cara tan caballa?"

Taylor sonrió. Aquella dislexia oral forzada era de las cosas más entretenidas que Bradley hacía cuando 
estaba borracho. Eso y sus intentos a la hora de bailar. "Siempre hago gestos cuando fumo. Es así como evito que la gente me pida cigarrillos. ¿Qué no te habías dado cuenta?"

"Sí, sí lo había notado. Que por cierto..." Y sonrió de la manera desinhibida y encantadora de la que sólo era capaz borracho (Taylor ya había intentado que la repitiera sobrio, pero él siempre se revertía a su mueca de labios apretados, escondiendo los dientes) mientras ella sacaba sus cigarrillos y el encendedor de su bolso. "¿Y pues qué haces aquí? Como que la fiesta es adentro de la casa".

"Lo sé," Dijo Taylor. "Sólo salí a tomar aire".

Bradly inhaló prolongadamente, se contuvo y soltó la bocanada. "Vaya aire fresco".

Ella sacó la lengua. "No me juzgues. Además, las cosas se están poniendo demasiado cachondas para mi gusto. Después de la tercera vez que tuve que empujar a Mitch lejos de mi "honky-tonk badonk-a-donk", como tan elegantemente lo llama, me di cuenta que debía descansar un rato de la pista de baile".

"Te entiendo", dijo Bradley. Ya un poco cansado de estar de pie y de mecerse, tomó asiento en el columpio y siguió hablando con Taylor desde lejos. "¿Quieres que le diga algo?"

"No, está bien. La música que han puesto es terriblemente ordinaria de todas formas".

"¡Hipster!” Exclamó Bradley, conteniéndose la risa mientras que intoxicaba sus pulmones con más humo. "¿Qué gustas? ¿Que pongan a LCD Soundsystem en el estéreo?"

"Pues no me vendría mal," Dijo ella "pero estaría bien un poco más de diversidad en cuanto al electropop se refiere. Digo, una sólo soporta 'Party Rock Anthem' un cierto número de veces antes de vomitar por todos lados".

"De hecho a mí me preocupaba más 'Shots'“. Dijo Bradley. "Parker y yo hicimos un pacto en el que cada vez que toquen esa canción, tenemos que tomarnos una ronda. Según mis cálculos, ya llevamos como seis".

"No mames, pues ya deberías de pararlo". Parker pesaba unas cuarenta libras menos que Bradley, aunque a él no le gustaba señalarlo.

"Pues yo creo que ahorita anda arriba con Sarah, así que podríamos decir que él se paró sólo".

"Tú podrías decir eso. Pero yo no. Me parece que eso levantaría más preguntas que las que yo estoy dispuesta a contestar". Un silencio incómodo interrumpió sus risas. Bradly se recargó hasta atrás del columpio y le sonrió al aletargado ventilador mientras Taylor consumía su fino tabaco hasta la colilla para luego clavarlo en una maceta. Se quedó observando los gestos de Bradley por un rato, y cuando él volteó a verla a ella, aún sonriendo, ella volteó torpemente y tomó su bolso para sacar otro cigarrillo. Al sacar la cajetilla ella volvió a ver a Bradley, quien aún la miraba con su estúpida sonrisa.

"Ven acá," Dijo él. "Y deja esos clavos de ataúd. ¿No te quieres convertir en una fumadora compulsiva como tu papá, verdad?"

Ella guardó la cajetilla, pero se quedó donde estaba. No volteó a ver a Bradley.

"Aww, anda". Bradley se puso de pie. "No seas así". Aún tenía su sonrisa puesta, pero era más como su sonrisa sobria y reprimida. "Anda, Taylor, habla. ¿Qué pasa?"

Ella por fin volteó a verlo. "¿Recuerdas aquella vez que nos metimos al campo de fútbol adentro de la 
prepa como a la una de la madrugada?"

"¿Oh, te refieres a 'La junta del comité en la yarda 50’? Sí, lo recuerdo".

"No, fue otra ocasión. Esa vez fue en el verano cuando recién entramos a la universidad, después de que te empezara a gustar la mota. Yo hablo del verano anterior a ese, después de la graduación". Dijo Taylor. No parecía estarlo captando, así que se puso de pie, se sentó junto a él en el columpio, y dijo "Fue con Travis y Sean..."

“¡Ah, y Lauren y Jeremy y todos esos! ¡Mierda, ya me acuerdo!” Él alzó su cigarrillo con la mano derecha y empezó a dibujar en el aire. Apenas y lo había fumado pero ya era casi todo cenizas. "Esa fue mi última noche antes de irme. Ahí estábamos todos sobre aquella manta, hablando y conversando y platicando y a veces agachándonos para que no nos viera el guardia de seguridad que pasaba cada media hora, cuando llegó la tormenta más feroz de todo el año”. "¡Mjm!” Taylor afirmó con la cabeza, y movió su brazo para imitarlo. "Veíamos a los rayos acercarse más y más, y escuchábamos rugir a los truenos, cerca y cerca y más cerca..."

"¡Hasta que me cayó una pinche gota de lluvia gigante en la cara!” Dijo Bradley, riéndose. "Luego pegamos la carrera a mi coche y nos escondimos ahí como por dos horas".

"Exacto". Dijo Taylor, mientras que dejaba su brazo caer y se recargaba sobre Bradley. "¿Qué fue de esa carcacha oxidada?"

"La choqué durante el primer año en la uni. Quedó desecha la pobre. Gracias a Dios no fue mi culpa, pero por algo pasan las cosas. Terminé por comprar un coche barato con lo del seguro y no he manejado una SUV desde entonces".

"Qué lástima. Echo de menos ese coche". Dijo ella con nostalgia en la voz. Ninguno de los dos habló por un momento, pero el silencio se volvió menos incómodo. De pronto Bradley irrumpió al decir, "¿Por qué quisiste saber si recordaba aquello?"

Taylor tuvo que pensar seriamente en lo que iba a decir antes de contestar. Se escuchaba una canción de Ke\$ha en el fondo mientras que ella organizaba sus palabras.

"Siento que cuando piensas en Arlington, estás pensando en el Arlington de aquel verano, y es como si el ahora y este lugar no fueran reales para ti. Como si, todo lo que pasó desde que te fuiste... nunca pasó".

"¿A qué te refieres?" Preguntó Bradley.

"Me refiero que cada vez que regresas, tienes la expectativa de que las cosas sean tal y como las dejaste. Esperas que yo sea la persona que era cuando te fuiste. Y yo trato de cooperar, de dejarlo todo para que te puedas divertir durante el mes o la semana por la que te quedas". Taylor se soltó del brazo de Bradley al inclinarse hacia adelante, y él observó su nuca, percatándose de la cadencia de su cabello mientras ella hablaba. "Y luego te vas. Y yo sigo aquí. Las cosas aquí son diferentes de como lo son para ti. Tengo un nuevo trabajo y nuevos amigos y... una nueva vida, aquí. Y tú no eres parte de eso. De modo que cuando regresas, tengo que vestirme con una piel nueva sólo para ti".

"Taylor..." Bradley trató de hablar inclinándose hacia adelante de nuevo, pero ella se puso de pie para encararlo en el columpio cruzando los brazos.

"¡Y ya estoy harta! No puedo seguir así. Necesito seguir adelante con mi vida, Bradley, y cada vez 
que vuelves retrocedo un poco más, me anclo en el pasado y ya no puedo vivir así." Se empezaron a formar lágrimas en el borde de sus ojos. "Lo siento, Bradley, pero necesito que te marches de mi vida y que permanezcas lejos".

Bradley agachó su mirada hacia sus manos, cruzándolas y apretando sus dedos sin decir nada, como si tratará de olvidar que Taylor estaba parada ahí enfrente, pero nadie podría ignorarla. "Está bien". Dijo Bradley. "La próxima vez que me vaya no volveré. Ya no tendrás que verme otra vez. Ya podrás seguir con tu vida y olvidarme. ¿Eso es lo que quieres?"

Mientras que ella esperaba alguna reacción por parte de él, sus lágrimas se habían secado ante el enojo y la impaciencia, pero ahora empezaban a surgir de sus ojos otra vez. "Sí". "Pues está bien". Bradley se puso de pie y encaró a Taylor incómodamente, como pensando si debiera intentar abrazarla una última vez, antes de escapar y regresar a la casa. "Shots (con Lil John)" empezó a sonar otra vez y Taylor podía escuchar a Bradley incorporarse de una manera extrañamente precisa al grito de "iEstoy bien pinchi peeeeeeeeedOOOOOOOO!"

Taylor se sentó en el columpio y encendió otro cigarrillo. Empezaba a llover en las calles, pero las mejillas de Taylor estaban secas. La época para las lágrimas había terminado.

Traducción de Brian Durán Fuentes 